\title{
Distinct roles for PTEN in prevention of T cell lymphoma and autoimmunity in mice
}

\author{
Xiaohe Liu, ${ }^{1}$ Jodi L. Karnell,, ${ }^{1}$ Bu Yin, ${ }^{2}$ Ruan Zhang, ${ }^{1}$ Jidong Zhang, ${ }^{1}$ Peiying Li, ${ }^{1}$ Yongwon Choi, ${ }^{3}$ \\ Jonathan S. Maltzman, ${ }^{1}$ Warren S. Pear, ${ }^{3}$ Craig H. Bassing, ${ }^{2}$ and Laurence A. Turka ${ }^{1}$ \\ 1Department of Medicine, University of Pennsylvania, Philadelphia, Pennsylvania, USA. 2Department of Pathology, Children's Hospital of Philadelphia, \\ Philadelphia, Pennsylvania, USA. ${ }^{3}$ Department of Pathology, University of Pennsylvania, Philadelphia, Pennsylvania, USA.
}

\begin{abstract}
Mutations in the tumor-suppressor gene phosphatase and tensin homolog deleted on chromosome 10 (Pten) are associated with multiple cancers in humans, including $\mathrm{T}$ cell malignancies. Targeted deletion of Pten in $T$ cells induces both a disseminated "mature phenotype" lymphoma and a lymphoproliferative autoimmune syndrome in mice. Here, we have shown that these two diseases are separable and mediated by $T$ lineage cells of distinct developmental stages. Loss of PTEN was found to be a powerful driver of lymphomagenesis within the thymus characterized by overexpression of the $c$-myc oncogene. In an otherwise normal thymic environment, PTEN-deficient $T$ cell lymphomas invariably harbored RAG-dependent reciprocal $t(14: 15)$ chromosomal translocations involving the $T$ cell receptor alpha/delta locus and $c-m y c$, and their survival and growth was TCR dependent, but Notch independent. However, lymphomas occurred even if TCR recombination was prevented, although these lymphomas were less mature, arose later in life, and, importantly, were dependent upon Notch pathways to upregulate c-myc expression. In contrast, using the complementary methods of early thymectomy and adoptive transfers, we found that PTEN-deficient mature $T$ cells were unable to undergo malignant transformation but were sufficient for the development of autoimmunity. These data suggest multiple and distinct regulatory roles for PTEN in the molecular pathogenesis of lymphoma and autoimmunity.
\end{abstract}

\section{Introduction}

Phosphatase and tensin homolog deleted on chromosome 10 (PTEN) was first functionally characterized as a lipid phosphatase that catalyzes the reverse reaction of PI3K $(1,2)$. The major substrate of PTEN is phosphatidylinositol-3,4,5-triphosphate $\left[\mathrm{PI}(3,4,5) \mathrm{P}_{3}\right.$, commonly referred to as $\left.\mathrm{PIP}_{3}\right]$, a second messenger produced following activation of PI3K via any one of a number of cell surface receptor/growth factor pathways. It has been proposed that PTEN exerts its tumor-suppressor and other functions by preventing accumulation of $\mathrm{PIP}_{3}$, thus limiting and/or terminating activation of a cascade of PI3K-dependent signaling molecules including the serine-threonine kinase Akt, the phosphatidylinositol-dependent kinases (PDKs), S6 kinase, and mammalian target of rapamycin (mTOR), as well as small GTPases Rac1 and Cdc42 (3).

PTEN has been implicated both in sporadic malignancies and in inherited cancer susceptibility syndromes. Large-scale studies have revealed loss of heterozygosity (LOH) at the PTEN locus in up to $50 \%$ of primary tumors tested, making it one of the most commonly mutated genes in human cancer (4). The tumors with the highest rate of $\mathrm{LOH}$ included glioblastoma (75\%), kidney carcinoma (40\%), prostate cancer (42\%), melanoma (48\%), and lung cancer (37\%). Germline mutations of PTEN are implicated in up to $80 \%$ of patients with Cowden disease, an inherited disorder characterized by multiple hamartomas and an increased risk of cancer, particularly breast, prostate, and thyroid cancers (5). These mutations include point mutations, deletions, insertions, and splice site mutations that span the entire length of the PTEN

Authorship note: Xiaohe Liu and Jodi L. Karnell contributed equally to this work.

Conflict of interest: Laurence A. Turka declares conflicts from GlaxoSmithKline (GSK), Myriad Genetics, and Novartis. Jonathan S. Maltzman declares conflicts from Amgen and GSK.

Citation for this article: J Clin Invest. 2010;120(7):2497-2507. doi:10.1172/JCI42382. gene $(5,6)$. Of note, a substantial subset of human $\mathrm{T}$ cell acute lymphoblastic leukemias are associated with mutations in PTEN (7-9). This is consistent with a murine model, in which mice with a deletion of Pten targeted to the $\mathrm{T}$ cell compartment (using either CD4-Cre or Lck-Cre) uniformly developed $\mathrm{T}$ cell lymphomas by $10-16$ weeks of age (10-13).

Loss of PTEN also has been shown to affect $\mathrm{T}$ cell signaling and homeostasis. PTEN-deficient murine $\mathrm{T}$ cells are hyperresponsive to TCR stimulation, do not require CD28 costimulation for optimal responses (14), show exaggerated activation of the PI3K and Erk pathways, and have elevated expression of $\mathrm{Bcl}-\mathrm{xL}(11,14)$. Consistent with effects on signaling and survival, PTEN is required for optimal negative selection in the thymus. These findings have suggested that loss of PTEN in T cells might result in autoimmunity. This is supported by the observation that $\mathrm{Pten}^{+/-}$mice develop a polyclonal autoimmune disorder associated with defective Fasmediated apoptosis (15) and that young mice in which the Pten deletion is targeted to $T$ cells have elevated levels of anti-singlestranded DNA Abs (11).

Most importantly, the mechanistic relationship(s) of the tumorand autoimmune-suppressing functions of PTEN in T cells have not been defined to date. Here, we show that these two diseases are separable and mediated by $\mathrm{T}$ lineage cells of distinct developmental stages. Lymphomas arise within the thymus and are characterized by overexpression of the $c-m y c$ oncogene, driven either by a chromosomal translocation event in the presence of RAG-mediated recombination, or, notably, via Notch (in the absence of RAG). In contrast, mature $\mathrm{T}$ cells deficient in PTEN never undergo malignant transformation, but cause severe multiorgan autoimmunity. These data show distinct regulatory roles for PTEN in the molecular pathogenesis of lymphoma and autoimmunity and highlight how mutations in this gene can lead to diverse context-dependent outcomes within a single-cell lineage. 
A

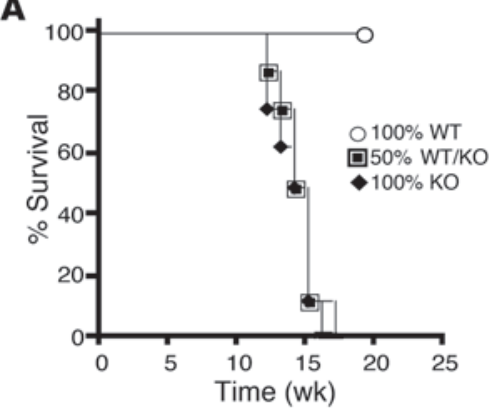

D

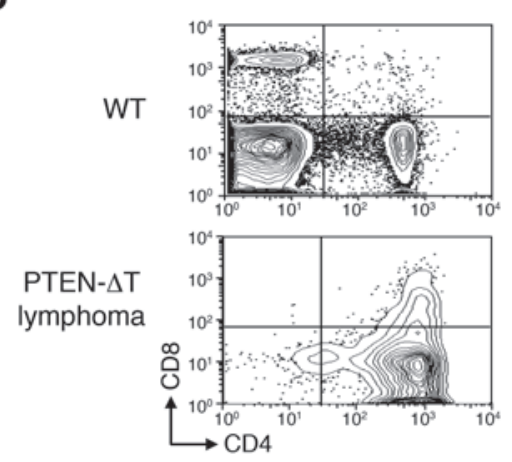

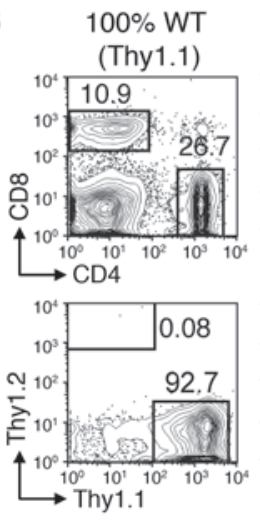

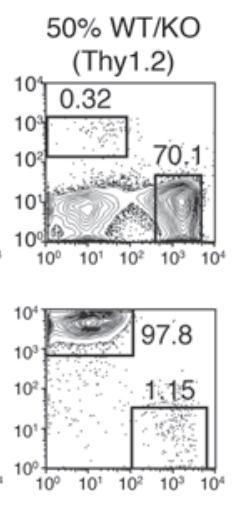

C

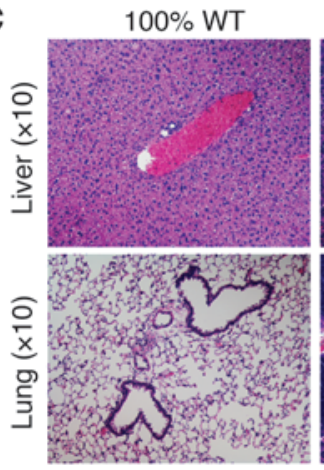

$50 \% \mathrm{WT} / \mathrm{KO}$

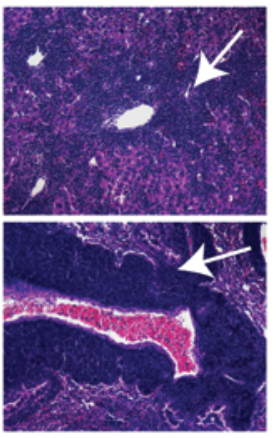

$\mathrm{CD}^{+}+$
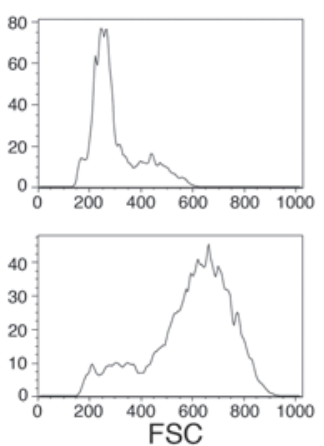
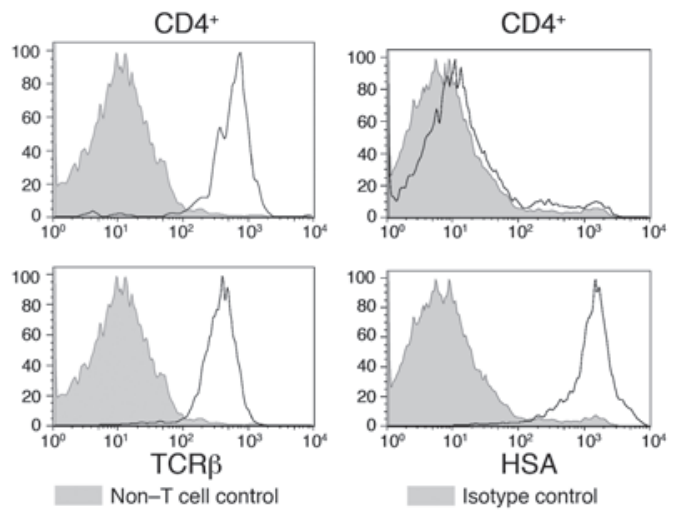

Figure 1

Lymphomagenesis in PTEN- $\Delta$ T mice is T cell intrinsic. (A) Bone marrow chimeras were prepared by transplanting bone marrow from WT mice $(n=4)$, PTEN- $\Delta$ T mice $(n=4)$, or a 50:50 mixture of the two $(n=8)$ into lethally irradiated WT congenic recipients. Survival of chimeric mice is measured in weeks after reconstitution. (B) Flow cytometric analyses of T cells in the spleen of representative chimeric mice from A and the contribution of WT (Thy1.1) and PTEN- $\Delta$ T (Thy1.2) bone marrow to the peripheral CD4 population. (C) H\&E staining of liver and lung from representative chimeric mice 15 weeks after reconstitution. (D) Immunophenotype of lymphoma cells in PTEN- $\Delta T$ mice. Cells from lymphoid organs of 10- to 17-week-old PTEN- $\Delta$ T mice with CD4 single-positive lymphomas were stained with antibodies for TCR $\beta$ or HSA and analyzed by flow cytometry. Forward scatter (FSC) is an indicator of cell size. Data are representative of 5 experiments.

\section{Results}

Targeted deletion of PTEN in $\mathrm{CD} 4^{+} \mathrm{CD} 8^{+}$thymocytes induces a cell-intrinsic disseminated "mature" T cell lymphoma. Consistent with prior studies $(10,11)$, at approximately 6 weeks of age, CD4-Cre $\times$ Pten $n^{f / f l}$ mice (hereafter termed PTEN- $\Delta$ T mice) accumulated $\mathrm{CD} 4^{+} \mathrm{CD} 69^{+}$cells in secondary lymphoid organs and developed fatal lymphomas (with cell counts in secondary lymphoid organs 10- to 20-fold higher than controls) beginning at approximately 10 weeks of age. The lymphoma cells predominantly expressed $\mathrm{CD}^{+} \mathrm{CD} 8^{-}$, high levels of TCR $\beta$, and heat-stable antigen (HSA, CD24) and were larger (as indicated by greater forward light scatter), which is a phenotype consistent with semi-mature, CD4 single-positive T cells (Figure 1, A and D, and data not shown). To determine whether this syndrome was $\mathrm{T}$ cell intrinsic, we generated mixed bone marrow chimeras. Only animals receiving PTEN- $\Delta \mathrm{T}$ bone marrow died prematurely, with mononuclear $\mathrm{T}$ cell infiltrates of visceral organs (Figure 1, A and C). Furthermore, in the mixed chimeras (i.e., with $50 \%$ WT and 50\% PTEN- $\Delta$ T bone marrow) at 15 weeks after reconstitution, there was a marked predominance of $\mathrm{CD} 4^{+} \mathrm{T}$ cells, with virtually all the $\mathrm{T}$ cells present being derived from the PTEN- $\Delta \mathrm{T}$ bone marrow, rather than the Thy1.1+ WT bone marrow (Figure $1 \mathrm{~B})$. As the presence of PTEN- $\Delta \mathrm{T}$ bone marrow does not induce accumulation and expansion of cells derived from WT bone marrow, we conclude that lymphoma is $\mathrm{T}$ cell intrinsic.

PTEN-deficient T lymphomas harbor a reciprocal chromosomal translocation, $t(14 ; 15)$, involving the $T C R \alpha / \delta$ locus and the c-myc oncogene. Deletion of PTEN in murine hematopoietic stem cells results in T cell lymphoma in association with a $t(14 ; 15)$ chromosomal translocation involving the Tcra and c-myc loci (16), a translocation that is characteristic of a subset of human $T$ cell acute lymphoblastic leukemias (T-ALLs) (17). Spectral karyotyping (SKY) analysis of lymphoma cells from PTEN- $\Delta$ T mice revealed a $100 \%$ incidence of a reciprocal 14;15 translocation and varying degrees of aneuploidy primarily involving the translocation products (Figure $2 \mathrm{~A}$ and Table 1 ). $\mathrm{t}(14 ; 15)$ translocations were found in thymocytes of healthy-appearing 6-week-old PTEN- $\Delta$ T mice (18\%-97\% of metaphases), whereas they were barely detectable in peripheral splenic and lymph node $\mathrm{T}$ cells $(0 \% \sim 1.8 \%)$ from the same mouse $(n=3)$, suggesting that the malignant population arises within the thymus and takes several weeks to exit and populate the periphery in detectable numbers. Similarly, c-myc expression was readily detected by Western blotting in thymic T cells of 6-week-old PTEN- $\Delta \mathrm{T}$ mice, but not in the periphery or in thymuses of littermate controls (Figure 2B). These differences were not a result of different $\mathrm{T}$ cell subset distributions 
A

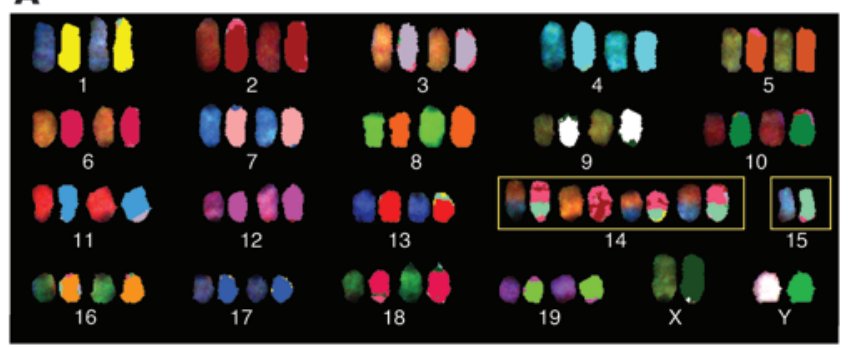

B

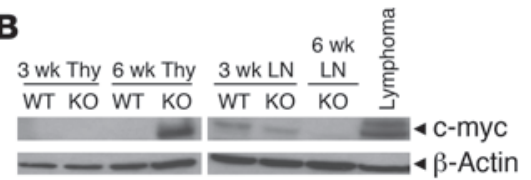

(Supplemental Figure 1; supplemental material available online with this article; doi:10.1172/JCI42382DS1). Elevated expression of c-myc was not associated with obvious gene amplification (Supplemental Figure 2), suggesting transcriptional and/or epigenetic regulation, possibly via Tcro regulatory machinery. Thus, while loss of Pten in hematopoietic stem cells leads to malignant transformation in association with a TCR $\alpha / c-m y c$ translocation (16), the present data demonstrate that PTEN acts to prevent $t(14 ; 15)$ lymphoma development well after $\mathrm{T}$ lineage commitment.

$t(14 ; 15)$ lymphomas are TCR dependent. The process of $\mathrm{V}(\mathrm{D}) \mathrm{J}$ recombination assembles Tor gene segments via double-strand break (DSB) intermediates during T cell thymic development (18). We hypothesized that RAG-mediated DSBs contributed to the development of lymphoma in PTEN- $\Delta \mathrm{T}$ mice by enabling the generation of TCR $\alpha /$ myc translocations. To test this, we crossed PTEN- $\Delta \mathrm{T}$ mice onto the recombination-deficient Rag $^{1 /-}$ background and introduced the OT-II TCR transgene as well to enable developing thymocytes to pass the $\beta$-selection (and TCR) checkpoint and progress to the double-positive stage where the floxed Pten gene could be deleted by CD4-Cre, and thence to further survive and migrate into the periphery.

Control TCR-transgenic, RAG-sufficient mice (OT-II/PTEN$\Delta \mathrm{T}-$ Rag $^{1+/}$ or OT-II/PTEN- $\Delta \mathrm{T}$-Rag $\left.1^{+/-}\right)$developed lymphomas (Figures 3, A and B, and Tables 2 and 3) similar to those of

\section{Figure 2}

$\mathrm{t}(14 ; 15)$ translocations and c-myc activation in lymphomas from PTEN$\Delta \mathrm{T}$ mice. (A) Detection of $\mathrm{t}(14 ; 15)$ by SKY analysis in metaphases from lymphoma cells in lymph nodes of diseased PTEN- $\Delta$ T mice (>9 wk). Note that distinct colors in a single chromosome are indicative of a translocation. Similar results were seen in lymphoma cells isolated from the spleen. Image shown is representative of total of 127 metaphases from 5 mice examined. (B) Western blot analysis of c-myc expression in tumor cells from the thymus (Thy) or lymph node (LN).
non-TCR-transgenic animals, indicating that skewing of the $T$ cell repertoire did not prevent malignant transformation. Interestingly, 50\% percent of OT-II/PTEN- $\Delta \mathrm{T}-\operatorname{Rag} 1^{-/-}$mice developed $\mathrm{CD}^{+} \mathrm{CD}^{+}$thymic lymphomas, with a median survival time of 18 weeks (Figure $3 \mathrm{~A}$ ). In contrast to the lymphomas of a semi-mature phenotype observed in PTEN- $\Delta \mathrm{T}$ and OT-II/PTEN- $\Delta \mathrm{T}-\mathrm{Rag}^{+/+}$mice, thymic lymphomas from OT-II/PTEN- $\Delta \mathrm{T}-$ Rag $1^{-/-}$mice had a less mature phenotype characterized by low levels of TCR $\beta$ expression (compare Figure 3B and Figure 1D) but continued high HSA expression. In addition, in contrast to lymphomas from PTEN- $\Delta \mathrm{T}$ recombination-sufficient animals, the tumor was exclusively limited to the thymus; all peripheral lymphoid organs were relatively T lymphopenic but tumor free (data not shown). Finally, SKY analyses revealed that none of these tumors had $t(14 ; 15)$ clonal translocations or any other consistent abnormality, although aneuploidy/polyploidy was readily apparent in OT-II/PTEN- $\Delta$ TRag1 $1^{-/}$tumors (Figure $3 \mathrm{C}$ and Tables 2 and 3). Taken together, these data indicate that RAG gene expression is necessary for the formation of $\mathrm{t}(14 ; 15)$ lymphomas.

To determine whether TCR signaling and TCR $\alpha$ recombination was required for tumor formation in the absence of PTEN, we used mice with conditional targeting of the TCR adaptor molecule SLP76 (19) and also crossed the PTEN- $\Delta$ T mice onto a TCR $\alpha$-deficient background. Previous studies have shown

Table 1

SKY analysis of tumors of PTEN- $\Delta$ T mice

\begin{tabular}{|c|c|c|c|c|c|}
\hline Mouse & $\begin{array}{l}\text { otal metaphases } \\
\text { examined }\end{array}$ & $\begin{array}{c}\text { Clonal } \\
\text { translocations }\end{array}$ & Frequency & $\begin{array}{l}\text { Confirmed by } \\
\text { TCR } \alpha / \delta \text { FISH }\end{array}$ & $\begin{array}{l}\text { Nonclonal translocations } \\
\text { and other abnormalities }\end{array}$ \\
\hline 53008 (12-wk-old) & 16 & $\begin{array}{l}2 \text { copies of } t(15 ; 14) ; 1 \text { copy of } t(14 ; 15) \\
2 \text { copies of } t(15 ; 14) ; 2 \text { copies of } t(14 ; 15)\end{array}$ & $\begin{array}{c}12 / 16(75 \%) \\
4 / 16(25 \%)\end{array}$ & Yes & None \\
\hline 60308B (11.5-wk-old) & 31 & $\begin{array}{l}3 \text { copies of } t(15 ; 14) ; 1 \text { copy of } t(14 ; 15) \\
3 \text { copies of } t(15 ; 14) ; 2 \text { copies of } t(14 ; 15) \\
2 \text { copies of } t(15 ; 14) ; 1 \text { copy of } t(14 ; 15) \\
2 \text { copies of } t(15 ; 14) ; 2 \text { copies of } t(14 ; 15)\end{array}$ & $\begin{array}{c}16 / 31(51.6 \%) \\
13 / 31(42 \%) \\
1 / 31(3.2 \%) \\
1 / 31(3.2 \%)\end{array}$ & Yes & $\begin{array}{l}\text { Occasional gain or loss } \\
\text { of Chr } 19 \text { and/or Chr Y }\end{array}$ \\
\hline 60308A (13-wk-old) & 32 & 2 copies of $t(15 ; 14) ; 1$ copy of $t(14 ; 15)$ & $31 / 32(96.9 \%)$ & Yes & None \\
\hline 52308 (15-wk-old) & 22 & 2 copies of $t(15 ; 14) ; 1$ copy of $t(14 ; 15)$ & $22 / 22(100 \%)$ & Yes & None \\
\hline 60308C (10-wk-old) & 26 & $\begin{array}{l}3 \text { copies of } t(15 ; 14) ; 1 \text { copy of } t(14 ; 15) \\
3 \text { copies of } t(15 ; 14) ; 2 \text { copies of } t(14 ; 15) \\
2 \text { copies of } t(15 ; 14) ; 2 \text { copies of } t(14 ; 15)\end{array}$ & $\begin{array}{c}15 / 26(57.7 \%) \\
10 / 26(38.5 \%) \\
1 / 26(3.8 \%)\end{array}$ & Yes & None \\
\hline
\end{tabular}


A
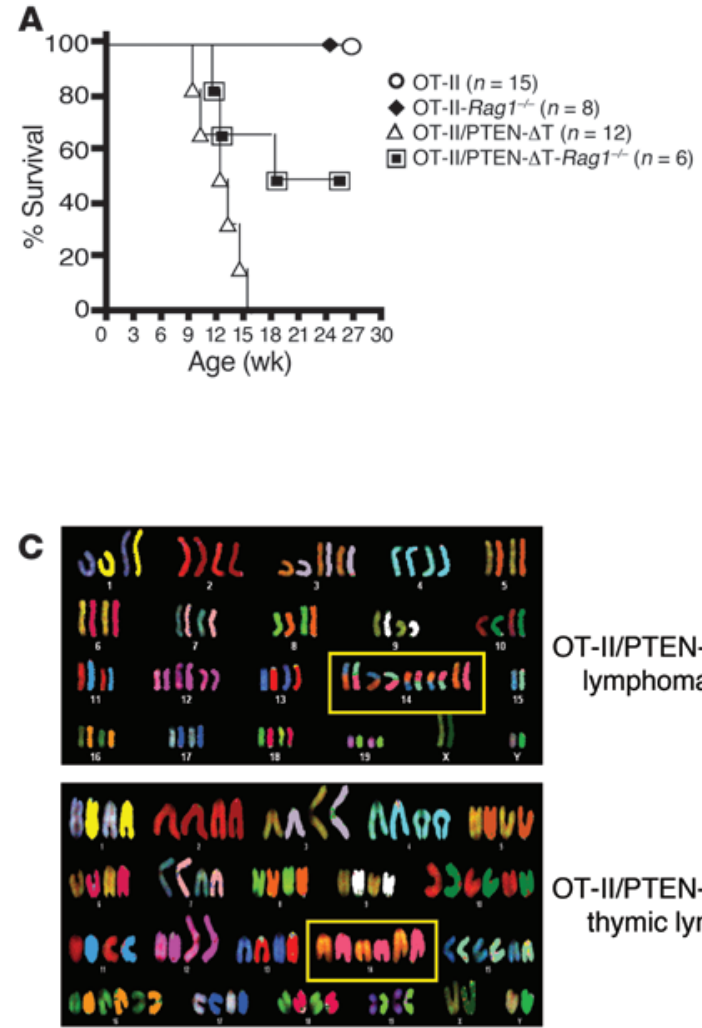

B
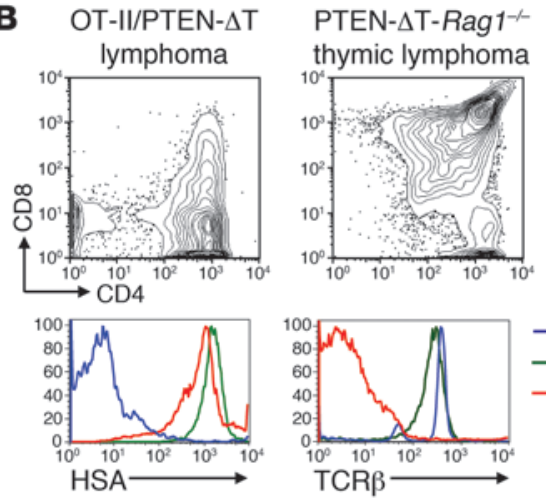

PTEN- $\Delta \mathrm{T}-$ Rag $1^{-/-}$
thymic lymphoma
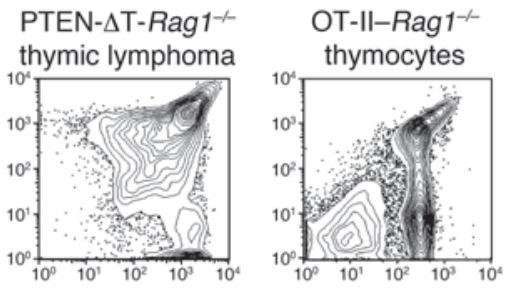
- OT-II-Rag 1-- peripheral CD4* T cells
OT-II/PTEN- $\Delta$ T lymphoma cells (CD4 $4^{*}$ )
- OT-II/PTEN- $\Delta$ T-Rag $1^{-\downarrow}$ thymic lymphoma cells (DP)
OT-II/PTEN- $\Delta$ T lymphoma

OT-II/PTEN- $\Delta$ T-Rag 1-thymic lymphoma

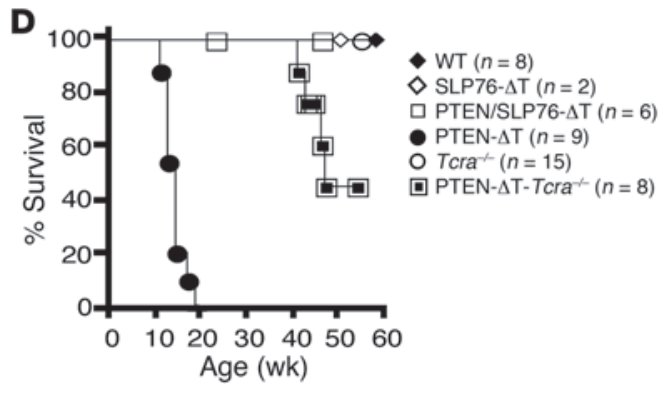

Figure 3

Lymphomagenesis in PTEN- $\Delta$ T mice defective in $V(D) J$ gene recombination or TCR signaling. (A) Survival of OT-II/PTEN- $\Delta$ T-Rag 1-l- mice and littermate controls. (B) Lymphomas from diseased OT-II/PTEN- $\Delta$ T and OT-II/PTEN- $\Delta$ T-Rag $1^{-/-}$mice and thymocytes from littermate controls were stained with the indicated antibodies and analyzed by flow cytometry. The data are representative of 3 independent experiments. DP, double-positive. (C) SKY analysis of lymphoma cells from OT-II/PTEN- $\Delta T-R a g 1^{-1-}$ mice and OT-II/PTEN- $\Delta$ T controls. Note that distinct colors in a single chromosome are indicative of a translocation. Image shown is representative of more than 91 metaphases from 3-5 mice per group. (D) Survival of PTEN/SLP76- $\Delta$ T and PTEN- $\Delta T-T_{c r a}{ }^{-/}$mice.

that adult $S L P 76^{f l / f l} \times C D 4$-Cre mice develop normal numbers of double-positive thymocytes but have only a few single-positive thymocytes due to a defect in positive selection (19). Peripheral $\mathrm{T}$ cells are reduced in number, have low cell surface TCR levels, and have profound deficiencies in activation and proliferation in response to TCR cross-linking. We generated Pten ${ }^{f l / f l} S L P 76^{f l / f l}$ mice and crossed them with CD4-Cre mice to generate PTEN/ SLP76- $\Delta \mathrm{T}$ mice and appropriate littermate controls. None of the 6 PTEN/SLP76- $\Delta$ T mice generated developed lymphomas with observation times up to 46 weeks (Figure 3D and Supplemental Figure 3A). Furthermore, SKY analysis of 257 metaphases from thymocytes and peripheral $\mathrm{T}$ cells from these mice did not detect any $\mathrm{t}(14 ; 15)$ translocations (Table 4$)$. Similar to OT-II/PTEN$\Delta \mathrm{T}-$ Rag 1 1/- animals, PTEN- $\mathrm{T}$-Tcra ${ }^{-/-}$mice (which can still rearrange $\mathrm{V} \alpha$ to $\mathrm{J} \alpha$, but do not assemble a full signaling-competent TCR $\alpha$ chain) developed $\mathrm{CD} 4^{+} \mathrm{CD} 8^{+}$thymic lymphomas at a late age, and $\mathrm{t}(14 ; 15)$ translocations were not detected (Figure $3 \mathrm{D}$, Supplemental Figure 3B, and Table 4). These data suggest that intact TCR signals are required for the formation of TCR $\alpha / \mathrm{c}$-myc translocations $[\mathrm{t}(14 ; 15)]$ in the absence of PTEN. Alternatively, it is possible that such translocations occur independently of TCR signaling, but that in the absence of TCR signals, the cells fail to expand and/or survive. However, the ability of cells to survive and undergo translocation-independent malignant transformation in the $\mathrm{Tra}^{-/-}$background argues against this latter possibility.

Immature, $t(14 ; 15)$-negative T cell lymphomas utilize Notch pathways to upregulate c-myc expression. We next performed a more detailed functional and phenotypic characterization the two types of lymphomas, i.e., those with and without the $t(14 ; 15)$ translocation (Figure 4 and Supplemental Figure 4). Notably, thymic lymphomas from both OT-II/PTEN- $\Delta \mathrm{T}-$ Rag 1-/- and PTEN- $\Delta \mathrm{T}-\mathrm{Tcra}^{-/-}$ mice, but not tumors from control PTEN- $\Delta \mathrm{T}$ mice, expressed pre-T $\alpha$ (Figure 4A). As pre-T $\alpha$ is a known Notch target (20), this suggested that $\mathrm{t}(14 ; 15)$-negative thymic lymphomas from these animals might share this common oncogenic pathway. Aberrant Notch1 signaling can directly induce c-myc expression (21-23) and is involved in more than $50 \%$ of cases of human $\mathrm{T}$ cell lymphomas (24) but has not been implicated in lymphomas induced by PTEN deficiency $(21-23,25)$. To investigate whether pre-T $\alpha$ expression in $\mathrm{t}(14 ; 15)$-negative thymic lymphomas is due to activated Notch1 signaling, we examined other Notch1 target genes, Hes-1 (26) and c-myc (21-23). In agreement with a previous report (16), Hes-1 expression was not elevated in PTEN- $\Delta \mathrm{T}$ tumors, which harbor $\mathrm{t}(14 ; 15)$ (Figure 4B). Strikingly, however, both Hes-1 and $c-m y c$ expression were markedly increased in $\mathrm{t}(14 ; 15)$-negative thymic lymphomas from PTEN- $\Delta \mathrm{T}$-Tcra-/- mice (Figure 4B) in the absence 
Table 2

SKY analysis of tumors of OT-II/PTEN- $\Delta$ T RAG-sufficient mice

\begin{tabular}{|c|c|c|c|c|}
\hline $\begin{array}{l}\text { Mouse and } \\
\text { genotype }\end{array}$ & $\begin{array}{l}\text { Total metaphases } \\
\text { examined }\end{array}$ & $\begin{array}{c}\text { Clonal } \\
\text { translocations }\end{array}$ & Frequency & $\begin{array}{l}\text { Nonclonal translocations } \\
\text { and other abnormalities }\end{array}$ \\
\hline $\begin{array}{l}30609, \\
\text { OT-II/PTEN- } \Delta \text { T-Rag1+/- } \\
\text { (14-wk-old) }\end{array}$ & Spleen, 44 & $\begin{array}{l}2 \text { copies of } t(15 ; 14) ; 2 \text { copies of } t(14 ; 15) \\
2 \text { copies of } t(15 ; 14) ; 1 \text { copy of } t(14 ; 15)\end{array}$ & $\begin{array}{l}42 / 44(95.5 \%) \\
2 / 44(4.5 \%)\end{array}$ & None \\
\hline \multirow[t]{2}{*}{$\begin{array}{l}\text { 52009, } \\
\text { OT-II/PTEN- } \Delta \text { T-Rag 1+/- } \\
\text { (12-wk-old) }\end{array}$} & Thymus, 43 & $\begin{array}{l}2 \text { copies of } t(15 ; 14) ; 1 \text { copy of } t(14 ; 15) \\
3 \text { copies of } t(15 ; 14) ; 1 \text { copy of } t(14 ; 15) \\
1 \text { copy of } t(15 ; 14) ; 1 \text { copy of } t(14 ; 15) \\
1 \text { copy of } t(15 ; 14) ; 1 \text { copy of complex } \\
\text { Chr } 14 / 15 \text { translocation }\end{array}$ & $\begin{array}{c}30 / 43(69.8 \%) \\
10 / 43(23.3 \%) \\
2 / 43(4.7 \%) \\
1 / 43(2.3 \%)\end{array}$ & None \\
\hline & Spleen, 35 & $\begin{array}{l}2 \text { copies of } t(15 ; 14) ; 1 \text { copy of } t(14 ; 15) \\
3 \text { copies of } t(15 ; 14) ; 1 \text { copy of } t(14 ; 15) \\
1 \text { copy of } t(15 ; 14) ; 1 \text { copy of } t(14 ; 15)\end{array}$ & $\begin{array}{c}26 / 35(74.3 \%) \\
7 / 35(20 \%) \\
1 / 35(2.9 \%)\end{array}$ & None \\
\hline \multirow[t]{2}{*}{$\begin{array}{l}\text { 42709, } \\
\text { OT-II/PTEN- } \Delta \text { T-Rag 1+/+ } \\
\text { (10-wk-old) }\end{array}$} & Thymus, 55 & $\begin{array}{l}2 \text { copies of } t(15 ; 14) ; 1 \text { copy of } t(14 ; 15) \\
2 \text { copies of } t(15 ; 14) ; 2 \text { copies of } t(14 ; 15) \\
3 \text { copies of } t(15 ; 14) ; 1 \text { copy of } t(14 ; 15) \\
1 \text { copy of } t(15 ; 14) ; 1 \text { copy of } t(14 ; 15)\end{array}$ & $\begin{array}{c}46 / 55(83.6 \%) \\
7 / 55(12.7 \%) \\
1 / 55(1.8 \%) \\
1 / 55(1.8 \%)\end{array}$ & None \\
\hline & LN, 55 & $\begin{array}{l}2 \text { copies of } t(15 ; 14) ; 1 \text { copy of } t(14 ; 15) \\
1 \text { copy of } t(15 ; 14) ; 1 \text { copy of } t(14 ; 15)\end{array}$ & $\begin{array}{c}54 / 55(98.2 \%) \\
1 / 55(1.8 \%)\end{array}$ & None \\
\hline $\begin{array}{l}\text { 20409, } \\
\text { OT-II/PTEN- } \Delta \text { T-Rag1+/+ } \\
\text { (13-wk-old) }\end{array}$ & Spleen, 53 & $\mathrm{t}(10 ; 14)$ & $39 / 53(73.6 \%)$ & None \\
\hline $\begin{array}{l}\text { 120108, } \\
\text { OT-II/PTEN- } \Delta \text { T-Rag1+/+ } \\
\text { (9-wk-old) }\end{array}$ & Spleen, 71 & $\begin{array}{l}2 \text { copies of } t(15 ; 14) ; 1 \text { copy of } t(14 ; 15) \\
2 \text { copies of } t(15 ; 14) ; 2 \text { copies of } t(14 ; 15) \\
3 \text { copies of } t(15 ; 14) ; 1 \text { copy of } t(14 ; 15)\end{array}$ & $\begin{array}{c}49 / 71(69 \%) \\
20 / 71(28.2 \%) \\
2 / 71(2.8 \%)\end{array}$ & Centromere fusion \\
\hline
\end{tabular}

of detectable c-myc genomic amplification (Supplemental Figure 2B). During normal T cell differentiation, Notch1 expression is high at the $\beta$-selection checkpoint and then downregulated as $\mathrm{T}$ cells further mature, and aberrant Notch 1 expression after $\beta$-selection can promote tumorigenesis $(27,28)$. Activating Notch1 mutations have been observed in multiple mouse models of T-ALL and commonly occur in the PEST domain, a region important for degradation of activated Notch (27). Therefore, we sequenced the Notch1 PEST domain in lymphomas from PTEN- $\Delta \mathrm{T}-\mathrm{Tcra}^{-/-}$mice but did not detect mutations ( $n=8$, data not shown). These data suggest that PTEN may regulate Notch $1 / \mathrm{c}$-myc expression at a transcriptional level, or alternatively, PTEN deficiency may permit Notch1-expressing double-negative (DN) thymocytes to bypass $\beta$-selection and promote tumorigenesis (29).

Loss of PTEN has been reported to confer Notch1 independence in human $\mathrm{T}$ cell leukemic cell lines (22). To further evaluate the dependency of $\mathrm{t}(14 ; 15)$-negative tumors on Notch signaling, we established spontaneously immortalized cell lines from PTEN- $\Delta \mathrm{T}$,

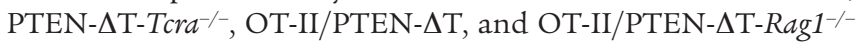

primary tumor cells. These cell lines were generally phenotypically similar to the tumors from which they were derived, although CD4 expression was lower on the PTEN- $\Delta$ T cell lines than in the primary tumors (Supplemental Figure 4). The $t(14 ; 15)$-negative

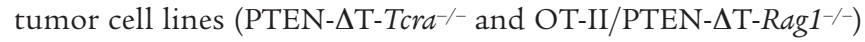
expressed elevated levels of CD25, another Notch signaling target (Figure 4C). Moreover, survival and growth were exquisitely sensitive to blockade of the Notch pathway by $\gamma$-secretase inhibition (GSI) (Figure 4D and data not shown). Cell cycle analyses showed that cell fractions in $\mathrm{G}_{2} / \mathrm{S} / \mathrm{M}$ phase were diminished, and fractions in sub- $\mathrm{G}_{0} / \mathrm{G}_{1}$ phase were markedly increased in GSI-treated PTEN$\Delta \mathrm{T}-\mathrm{Tcra}^{-/}$and OT-II/PTEN- $\mathrm{T}$-Rag1-/- cell lines [i.e., those without the $\mathrm{t}(14 ; 15)$ translocation; Figure $4 \mathrm{E}]$, but not in recombination-sufficient PTEN- $\Delta \mathrm{T}$ cell lines (derived from tumors with the translocation). Finally, lysates from PTEN- $\Delta$ T-Tcra-/- and OT-II/ PTEN- $\Delta \mathrm{T}$-Rag1 $1^{-/}$cell lines expressed S3-cleaved Notch1, indicative of active intracellular Notch signaling (Figure 4F). By contrast, Notch signaling was undetectable in both tumor cell lines derived from $t(14 ; 15)$ lymphomas for all assays described above.

\section{Table 3}

SKY analysis of tumors of OT-II/PTEN- $\Delta$ T RAG-deficient mice

\begin{tabular}{|c|c|c|c|c|}
\hline Mouse and genotype & $\begin{array}{c}\text { Total metaphases } \\
\text { examined }\end{array}$ & Aneuploidy & Diploidy & $\begin{array}{c}\text { Clonal } \\
\text { translocation }\end{array}$ \\
\hline 52809, OT-II/PTEN- $\Delta$ T-Rag1-/- (12-wk-old) & Thymus, 34 & 34/34; average chromosome number: 44 & $0 / 34$ & None \\
\hline 41009, OT-II/PTEN- $\Delta$ T-Rag1-/- (13-wk-old) & Thymus, 48 & 31/48; average chromosome number: 78 & $17 / 48$ & None \\
\hline 093009, 0T-II/PTEN- $\Delta$ T-Rag1-/- (25-wk-old) & Thymus, 9 & 9/9; average chromosome number: 79 & $0 / 9$ & None \\
\hline
\end{tabular}




\section{Table 4}

SKY analysis of PTEN- $\Delta \mathrm{T}-\mathrm{Tcra}^{--}$and PTEN/SLP76- $\Delta \mathrm{T}$ mice

\begin{tabular}{|c|}
\hline Mous \\
\hline $\begin{array}{l}\text { CD4-Cre } \times \text { Pten }^{+/+} \text {Tcra }^{-1-} \text { control thymus } \\
\text { (32-wk-old) }\end{array}$ \\
\hline CD4-Cre $\times$ Pten $^{f / / f I}$ Tcra $^{-1-1113 ~(16-w k-o l d) ~}$ \\
\hline CD4-Cre $\times$ Pten $^{f / / f I}$ Tcra $^{-1-} 1030$ (30-wk-old) \\
\hline CD4-Cre $\times$ Pten $^{f / / f}$ Tcra $^{-1-} 12909$ (42-wk-c \\
\hline PTEN/SLP76- $\Delta$ T 71309 (46-wk-old) \\
\hline
\end{tabular}

PTEN/SLP76- $\Delta$ T 81909 (36-wk-old)

$\begin{array}{cc}\begin{array}{c}\text { Total metaphases } \\ \text { examined } \\ \text { Thymus, } 32\end{array} & \begin{array}{c}\text { Reciprocal } \\ \text { translocation (14;15) }\end{array} \\ \text { Thymus, 109 } & \text { None } \\ \text { Thymus, 103 } & \text { None } \\ \text { Thymus, 41 } & \text { None } \\ \text { Spleen, LNs, 119 } & \text { None } \\ & \text { None } \\ \text { Thymus, 138 } & \text { None }\end{array}$

Frequency and abnormalities None None 1

None

Chr 19 fragment

$1 / 119$

Chr 2 fragment without centromere, also $t(4 ; 10), t(4 ; 13)$, and $t(10 ; 3)$

Chr X fragment
These data indicate that $\mathrm{t}(14 ; 15)$-mediated c-myc overexpression and Notch1-mediated c-myc overexpression are distinct oncogenic events in developing $\mathrm{T}$ cells, with resultant implications for drug sensitivity and treatment.

PTEN-deficient mature T cells are unable to undergo malignant transformation but are sufficient for the development of autoimmunity. Checkpoints that regulate malignancy have been shown to also regulate autoimmunity (30). Indeed, haploinsufficiency of PTEN promotes autoimmunity (15), and PTEN- $\Delta \mathrm{T}$ mice have defective thymic negative selection and laboratory findings consistent with autoimmune diseases, such an elevated anti-single-stranded DNA antibodies $(11,14)$. While the universal occurrence of $\mathrm{t}(14 ; 15)$ translocations in lymphomas that arose in PTEN- $\Delta \mathrm{T}$ mice made it likely that these were of thymic origin, the absence of these translocations in tumors from recombination-deficient animals suggested that tumors might arise from mature T cells as well.

To determine the relationship between autoimmunity and malignancy, and among cell maturity, activation, and transformation, we carried out adoptive transfer studies. Surprisingly, mature T cells in the periphery of 3-week-old PTEN- $\Delta$ T mice failed to undergo malignant transformation when placed into congenic hosts, including Rag1 $1^{-/}$animals, sublethally irradiated (5 Gy) mice, and unmodified mice (Figure 5A and data not shown). This was not due to cell loss or elimination of the cells, as PTEN- $\Delta \mathrm{T} T$ cells could still be detected for up to 1 year after adoptive transfer, without evidence of malignant transformation (Figure 5B and data not shown). In contrast, thymocytes of 6-week-old PTEN- $\Delta$ T mice were able to transfer lymphoma to Rag1 ${ }^{-/-}$recipients (Figure 5A), which is consistent with the above-noted presence of $t(14 ; 15)$ translocations in large numbers (18\%-97\%) of metaphases in this cell population.

The failure of mature $\mathrm{T}$ cells (Figure 5A) or thymocytes from 3 -week-old mice (data not shown) to undergo transformation strongly suggested that tumors arise exclusively within the thymus of animals older than 3 weeks. To test this hypothesis we thymectomized PTEN- $\Delta$ T mice at age 3-3.5 weeks. We observed that early thymectomy completely prevented lymphoma development (Figure $5 \mathrm{C}$ ). Consistent with a thymic origination of lymphoma, T cells in the thymus, but not the periphery, of a representative $(n=3)$ 6 -week-old mouse showed the presence of a monoclonal population, as evidenced by appearance of dominant $\mathrm{J} \beta 1$ and $\mathrm{J} \beta 2$ bands (Figure 5D). Furthermore, adoptive transfer of thymocytes, but not peripheral T cells, from 6-week-old mice into Rag1-/- recipients led to lymphoma development with $\mathrm{t}(14 ; 15)$ in 5-9 weeks (Figure $5 \mathrm{~A}$ and data not shown).

Interestingly, there was a 5- to 8-fold increase in splenic cellularity in 9- to 9.5-month-old thymectomized PTEN- $\Delta$ T mice $(n=7)$ compared with thymectomized age-matched controls $(n=4)$ (Figure $6 \mathrm{~A}$ ). The enlarged spleens in the thymectomized, PTEN- $\Delta$ T mice contained an increased percentage of $\mathrm{CD}^{+}$cells $(34.1 \% \pm 11.4 \%$ vs. $11.3 \% \pm 2.4 \% ; P=0.0106)$, the majority of which expressed CD 69 and PD-1, markers of acute and chronic activation, respectively (Figure $6 \mathrm{~B})$, and a decreased percentage of $\mathrm{B} 220^{+}$cells $(43.8 \% \pm 15.9 \%$ vs. $71.0 \% \pm 4.9 \% ; P=0.0264)$. Staining the T cell pool with a panel of antibodies specific for 12 different TCR V $\beta$ domains revealed normal TCR diversity (Figure 6B and Supplemental Table 1), indicating that $\mathrm{T}$ cell expansion in thymectomized mice without evidence of malignancy was polyclonal. Like the T cells, a large percentage of the $B$ cells in aged, thymectomized PTEN- $\Delta$ T mice had an activated phenotype, expressing elevated levels of CD86 and MHC class II (data not shown). The activated B cell phenotype correlated with increased levels of circulating antibodies, including a greater than 10 -fold increase in IgG1 in 9-month-old PTEN- $\Delta \mathrm{T}$ mice relative to agematched controls (Figure 6C). We used the Crithidia luciliae assay (31, 32 ) to test for anti-dsDNA antibodies in the sera of these mice. This is a highly specific test for anti-dsDNA Abs that relies on the fact that C. luciliae has a large amount of dsDNA specifically restricted to its kinetoplast. We found positive kinetoplast staining with sera from 9-month-old PTEN- $\Delta$ T mice $(n=6)$ but not age-matched controls $(n=4)$ (Figure $6 \mathrm{D})$. Among the PTEN- $\Delta \mathrm{T}$ cohort, positive staining was observed at a 1:1,000 titer in 2 mice, a 1:100 titer in 3 mice, and a 1:10 dilution in 1 mouse. Analysis of the peripheral tissues revealed extensive mononuclear cell infiltration in the liver, lung, and kidney of thymectomized PTEN- $\Delta \mathrm{T}$ mice (Figure $6 \mathrm{E}$ ). Last, consistent with the reported defect in $\mathrm{T}$ cells from $\mathrm{Pten}^{+-}$mice (15), T cells from PTEN- $\Delta$ T mice were relatively resistant to activation-induced cell death (AICD) (Figure 6F). Thus, PTEN deficiency in the $\mathrm{T}$ cell lineage causes two distinct events that arise within a single-cell lineage at different times: lymphomas that occur during T cell development within the thymus; and multiorgan autoimmunity, which results from aging mature peripheral $\mathrm{T}$ cells.

\section{Discussion}

PTEN is a complex protein with multiple distinct cytoplasmic and nuclear functions that regulate growth, metabolism, survival, cell 
A
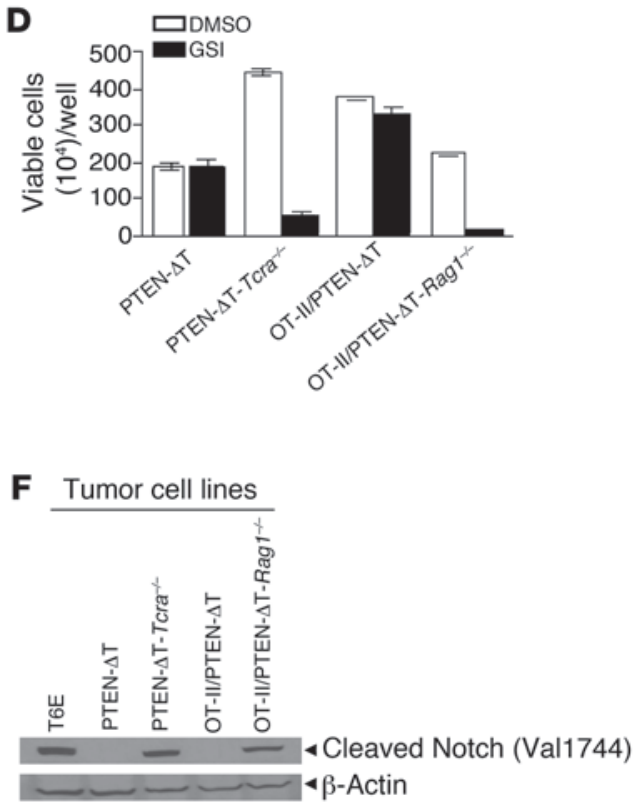

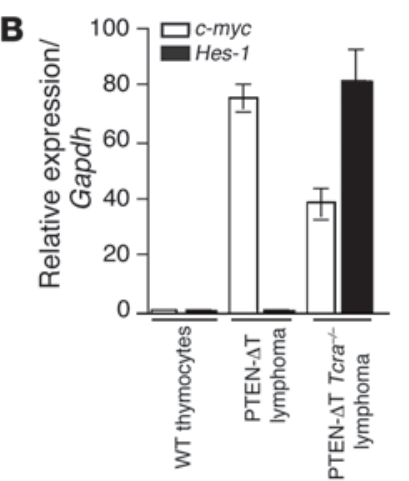

C

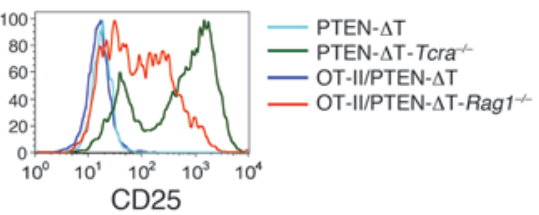

E
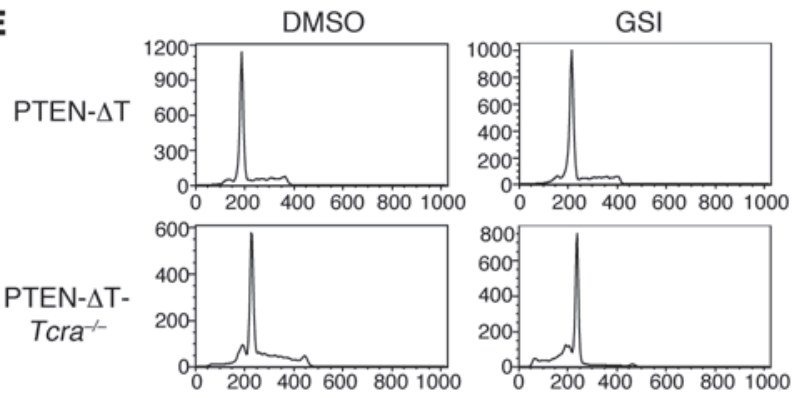

OT-III

PTEN- $\Delta T$
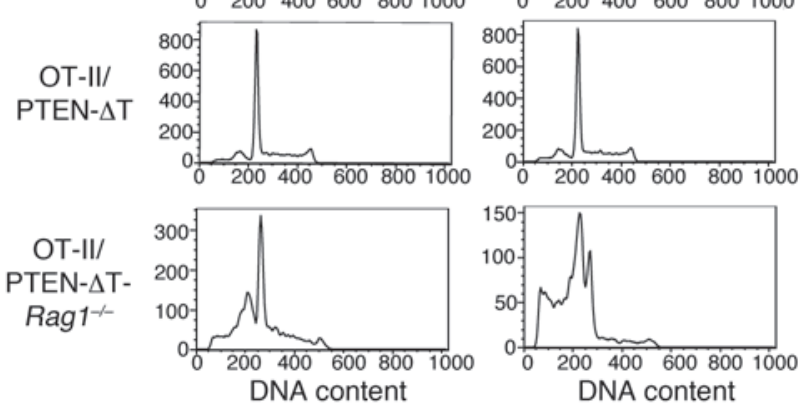

Figure 4

Activated Notch signaling in t(14;15)-negative lymphoma cells. (A) RT-PCR analysis of pre-T $\alpha(p T \alpha)$ expression in RNA isolated from the indicated cells. (B) Quantitative RT-PCR for Hes-1 and c-myc in WT thymocytes or indicated primary lymphoma cells normalized to Gapdh. (C) Flow cytometric analysis of CD25 expression in cell lines derived from the indicated primary lymphomas. (D) Growth suppression by GSI. The tumor cell lines derived from the indicated primary lymphoma cells were cultured with or without $1 \mu \mathrm{M} \mathrm{GSI} \mathrm{in} \mathrm{a} \mathrm{24-well} \mathrm{plate} \mathrm{for} 72$ hours. Graph shows the number of trypan blue-negative cells per well. (E) Impaired proliferation, cell cycle arrest, and apoptosis in $t(14 ; 15)$-negative tumor cell lines treated with GSI. (F) Western blot analysis of the activated form of Notch1 protein in the indicated cell lines. All experiments described in $\mathbf{C}-\mathbf{F}$ are representative of 6 or more different cell lines derived from at least 2 individual primary lymphomas.

migration, and genomic integrity (33). In T cells, these functions of PTEN prevent T cell-intrinsic autoimmunity and malignancy. It has been proposed that autoimmune disease may develop in $\mathrm{T}$ cells as a result of germline or somatic mutations (or both), which allow them to bypass critical tolerance checkpoints, similar to the process by which multiple mutations collectively lead to malignant transformation allowing cells to bypass anti-oncogenic checkpoints (30). Our studies demonstrate that germline mutation in a single gene, Pten, promotes the development of autoimmunity and lymphoma via distinct events within cells of the same lineage, but of differing ages/developmental stages.

The functional role of PTEN in lymphomagenesis is a topic of study and controversy. PTEN has been shown to undergo nuclear translocation following monoubiquitination and to complex with CENP-C to help maintain genomic integrity (34). It has been suggested that this function of PTEN is relevant to the finding that in its absence, murine $\mathrm{T}$ cell leukemia/lymphomas occur in otherwise normal animals in invariable association with a $\mathrm{t}(14 ; 15)$ translocation (16), and translocations involving the TCR $\alpha$ locus and c-myc are implicated in human $\mathrm{T}$ cell acute lymphocytic leukemia as well (35-38). Moreover, mutations in PTEN are common in human acute lymphoblastic leukemia (7-9) and frequently are truncation mutants that delete the CENP-C binding domain rather than mutations affecting the phosphatase domain (34). These findings suggest a model in which PTEN's role as a tumor-suppressor gene, at least in the case of T cells, is to prevent the development of genomic events that promote cell transformation.

However, an alternative model is that loss of PTEN is permissive for the survival of cells that, for other reasons, have acquired a $t(14 ; 15)$ translocation and that these events are jointly required for malignancy. Consistent with this, Hagenbeek et al. studied T cell development in Lck-Cre-Pten ${ }^{f / f l}$ mice (29). By crossing these mice with Rag2- and $\gamma c$-deficient mice, the authors showed that PTEN deficiency can substitute for both IL-7 receptor and pre- 
A

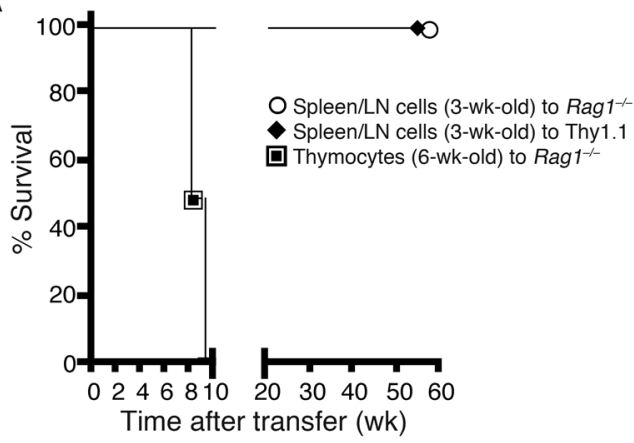

C

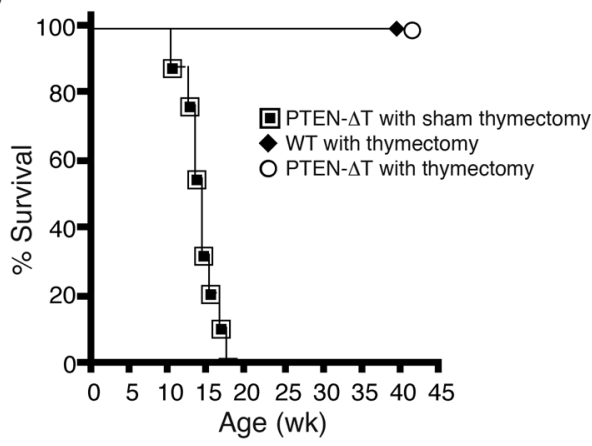

B
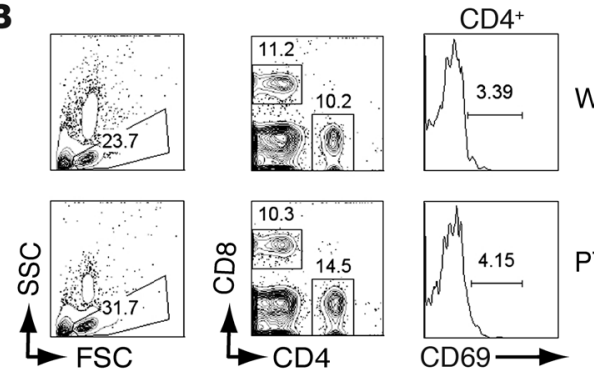

WT
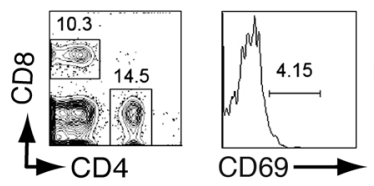

PTEN- $\Delta \mathrm{T}$

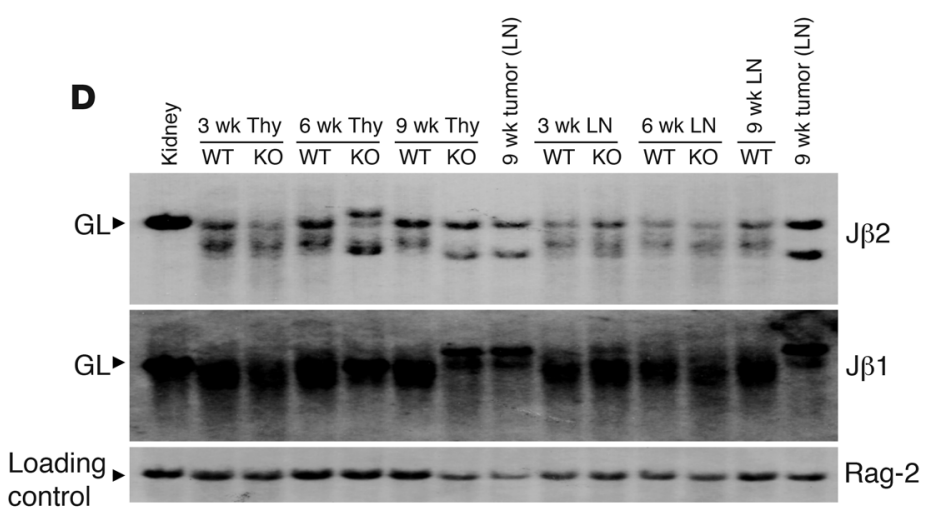

Figure 5

Requirements for lymphomagenesis and autoimmunity in PTEN- $\Delta$ T mice. (A) Rag1--- mice or sublethally irradiated B6 Thy1.1 mice were adoptively transferred with 5 million thymocytes or peripheral $T$ cells (purified from spleen or lymph node as indicated) from 3- or 6-week-old PTEN- $\Delta T$ Thy1.2 mice. (B) Lack of malignant transformation of T cells from 3- to 4-week-old PTEN- $\Delta$ T mice following adoptive transfer into Rag ${ }^{-/-}$mice at 100 days after transfer. (C) PTEN- $\Delta$ T or WT mice were thymectomized at 3.5 weeks of age and monitored for survival ( $n=9$ for each group). (D) Southern blot analysis of TCR $\beta$ rearrangement in genomic DNA of thymocytes. Paired thymocyte and LN T cell samples from mice of the indicated ages were obtained from the same individual mice. The sample of a lymphoma-bearing, 9-week-old PTEN- $\Delta \mathrm{T}$ mouse represents tumor cells. Germline configurations of mouse kidney DNA shown for comparison. Data are representative of 3 premalignant mice of each group and 6 tumors. Rag-2 is shown as a loading control.

TCR signals in the thymus. Higher basal PI3K signals maintained in the absence of PTEN likely promote survival and proliferation of developing thymocytes even in the absence of normally required environmental and cellular cues, bypassing the normal PDK1 checkpoint regulation of cell growth (13).

Further complicating the picture is the fact that the type of the lymphoma arising is context dependent, being modulated by the presence of recombination involving the TCR $\alpha$ locus and the competence of TCR signaling. While all lymphomas in our study were characterized by c-myc overexpression, in the presence of intact $\mathrm{V}(\mathrm{D}) \mathrm{J}$ rearrangement, TCR signaling, and TCR $\alpha$ expression, cis-activation of c-myc via a translocation induced a Notch1-independent $\mathrm{T}$ cell lymphoma, whereas in the absence of recombination, loss of PTEN leads to Notch1-dependent c-myc overexpression. Thus, PTEN might have distinct roles in the two cases or may alternatively have a final common pathway of synergizing with myc activation to lead to malignancy.

It is notable that the malignancy that develops in the absence of RAG not only lacks the $t(14 ; 15)$ translocation but is a thymusrestricted lymphoma without any evidence for peripheral dissemination. Previous studies have shown that RAG-induced DSBs, in addition to their role in $V(D) J$ recombination, play an important regulatory function for a wide variety of genes whose proteins are involved in lymphocyte development/function, such as CD40 and CD69 (39), and the loss of these RAG-mediated affects may underlie the differing types of lymphomas that develop in PTEN$\Delta \mathrm{T}$ mice versus PTEN- $\Delta \mathrm{T}-$ Rag $1^{-/}$mice.

We were surprised to find no evidence for lymphoma development or $\mathrm{t}(14 ; 15)$ translocations in mice under age $3-4$ weeks, consistent with related findings by Xue et al.; ref. 12). The reasons for this observation remain obscure. Given the known effects of age and sex hormones on the thymus, we considered the fact that sexual maturation might be required for lymphomagenesis. However, surgical castration of mice $(n=5)$ did not affect the incidence or timing of lymphoma development (data not shown).

Our data also provide new insights into the development of autoimmunity in the absence of PTEN. We find that loss of PTEN in $\mathrm{T}$ cells alone is sufficient to induce resistance to AICD and lead to multiorgan autoimmunity. This is associated with activation of B lymphocytes, which is thus shown to be cell extrinsic. While we cannot exclude a role for altered thymic selection (11) in the autoimmunity observed in PTEN- $\Delta$ T mice, the phenotype we observe is similar to that seen with fas or gld mutations in permissive genetic backgrounds and thus may be accounted for solely by resistance of T cells to AICD. In either event, although it cannot be at present be tested, it seems likely that if tumor-bearing mice could be cured of their lymphomas, they likely would develop autoimmunity later in life, given the separable nature of these events. 


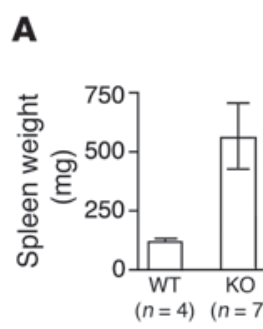

B

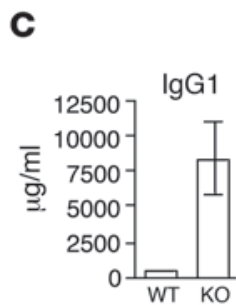

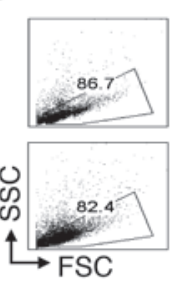

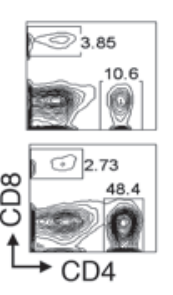

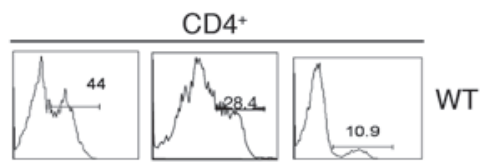

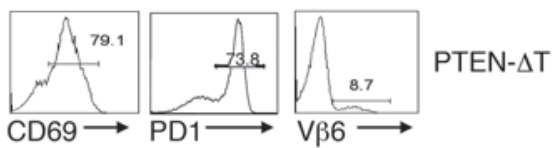

D

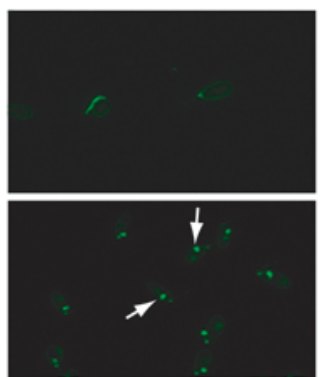

WT
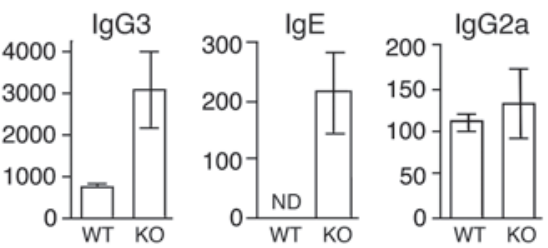

을

WT

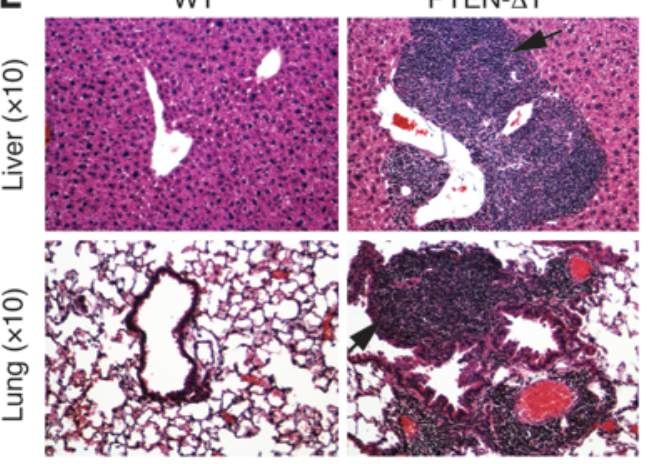

$\mathbf{F}$

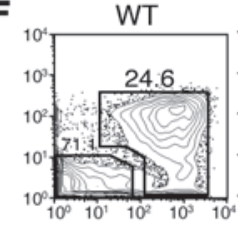
PTEN- $\Delta \mathrm{T}$
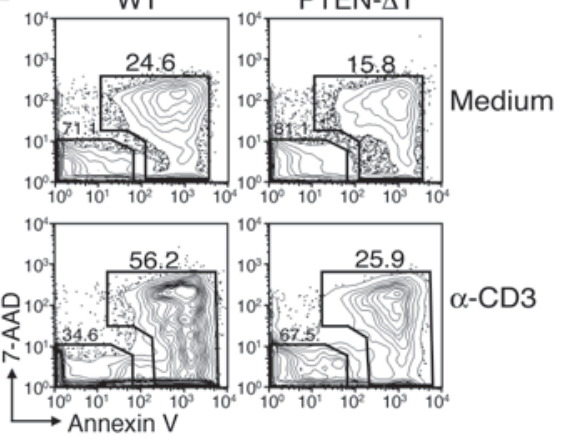

Figure 6

The development of autoimmunity in thymectomized PTEN- $\Delta$ T mice. (A) Representative splenic weights from thymectomized mice at 9.5-11 months of age. (B) WT and PTEN- $\Delta$ T mice that received a thymectomy were sacrificed at 9.5 months of age. Data represent lymphocyte profiles from the spleen of representative aged, thymectomized mice. (C) Elevated immunoglobulin levels from sera of 9.5-month-old thymectomized WT and PTEN- $\triangle$ T mice from B measured by ELISA. (D) Detection of serum dsDNA autoantibodies in 9.5-month-old thymectomized WT and PTEN- $\Delta$ T mice. Sera from the indicated mice was used to detect the presence of anti-dsDNA antibodies. Kinetoplast staining (as indicated by the arrow) indicates a positive antibody response to dsDNA. Original magnification, $\times 10$. (E) Representative H\&E staining of liver and lung of thymectomized WT and PTEN- $\Delta$ T mice at 9.5 months of age. All experiments described in A-E are representative of 4 mice of each group. (F) Defective AICD in PTEN-deficient CD4+ T cells. T cells were isolated from 3.5-week-old PTEN- $\Delta T$ and WT mice and cultured in the presence of $\alpha$-CD3, $\alpha$-CD28, and IL-2. Viable cells were fractionated and restimulated with $\alpha$-CD3 for an additional 16 hours, and cell death was evaluated by flow cytometry with the indicated markers gated on CD4+ population. The data are representative of 2 independent experiments on $\mathrm{T}$ cells from a total of 6 mice of each genotype.

\section{Methods}

Mice. CD4-Cre-Pten ${ }^{f / f l}(\mathrm{PTEN}-\Delta \mathrm{T})$ mice and OT-II mice were previously described (14). $S L P 76^{f l / f l}$ and $S L P 76^{-/-}$mice used to generate PTEN/ SLP76- $\Delta \mathrm{T}$ mice were previously described $(19,40)$. Tcra ${ }^{-/}$mice (41) were a gift of Terri Laufer (University of Pennsylvania). All of the above mice were backcrossed more than 12 generations onto a C57BL/6 background. C57BL/6 mice expressing the Thy 1.1 congenic marker and Rag1 $1^{-/-}$mice were purchased from the Jackson Laboratory. All animals were cared for according to the animal care guidelines of the University of Pennsylvania, and all experimental protocols were approved by Institutional Animal Care and Use Committee.

Mixed bone marrow chimeras. Mice were lethally irradiated (10 Gy) prior to reconstitution with $2 \times 10^{6}$ total T cell-depleted bone marrow cells at specified ratios from either WT (Thy1.1) or PTEN- $\Delta \mathrm{T}$ (Thy1.2) mice. Recipient mice were treated with Neosporin (DSM Pharmaceuticals Inc.) for 1 week prior to and 2 weeks after reconstitution.

Flow cytometry and cell sorting. Monoclonal antibodies specific for CD4 (GK1.5, RM4-5, L3T4), CD69 (H1.2F3), CD44 (IM7), CD24 (MI/69),

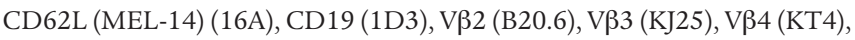

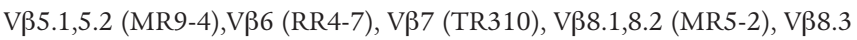

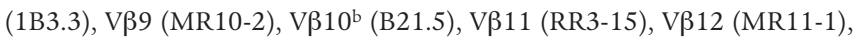
V $\beta 13$ (MR12-3), V $\beta 14$ (14-2), V $\beta 17^{\mathrm{a}}$ (KJ23). Annexin V, CD44-PE (IM7), Vo2 (B20.1), CD25 (PC61), CD90.1 (OX-7), CD8 $\alpha$ (clone 53-6.7), CD3 (145-2C11), CD90.2 (clone 53-2.1), and cell viability dye 7-AAD were purchased from BD. Antibodies were used as FITC, PE, PerCP-cy5.5, and allophycocyanin (APC) conjugates. Single-cell suspensions were prepared from blood, thymus, spleen, and lymph node. Cells were stained by standard methods, and events were collected on a FACSCalibur flow cytometer (BD) 
and analyzed using FlowJo software. In some instances, cells were sorted by a FACSAria (BD).

Tumor cell line derivation and culture. Single-cell suspensions were prepared from tumor-bearing thymus, spleen, or lymph nodes and cultured in RPMI 1640 with $10 \%$ fetal bovine serum. Primary tumor cells were plated at $2.5 \times 10^{6}$ cell per well in a 24 -well plate. Tumor cells were left undisturbed for 1 week and subsequently fed 3 times weekly. When nonadherent cells became confluent, they were split and transitioned to a $60-\mathrm{mm}$ dish and finally to a $25-\mathrm{cm}^{2}$ flask.

$\gamma$-Secretase inbibitor treatment. Compound $\mathrm{E}$ (Calbiochem), a potent $\gamma$-secretase inhibitor, was used to block Notch1-mediated signal transduction in primary tumor-derived cell lines. Cells in logarithmic growth were seeded at densities of $0.5 \times 10^{5}$ to $1 \times 10^{5}$ cells $/ \mathrm{ml}$ according to different growth rates and cultured in the presence of $1 \mu \mathrm{M}$ of compound $\mathrm{E}$ or mock (DMSO) for up to 3 days. At various time points after treatment onset, the effects of GSI on cell growth, cell viability, and cell cycle distribution were analyzed.

RNA analyses. RNA was extracted and purified using the RNeasy Mini Kit (QIAGEN). All RNA templates were subjected to DNase I digestion following the protocol in the kit. After reverse transcription, cDNA was subjected to PCR. Pre-T $\alpha$ expression was assayed using the following primers: forward, 5'-CTACCATCAGGCATCGCT-3', and reverse, 5'-CTATGTCCAAATTCTGTGGGTG-3'; $\beta$-actin primers: forward, 5'-GTGGGCCGCTCTAGGCACCAA- $3^{\prime}$, and reverse, $5^{\prime}$-CTCTTTGATGTCACGCACGATTTC-3'. For quantitative RT-PCR, reaction was performed using an $\mathrm{ABI} 7300$ machine (Applied Biosystems). c-myc and Hes-1 RNA expression was determined relative to Gapdh expression using the TaqMan Gene Expression Assay (Applied Biosystems). All quantitative RT-PCR analyses were done in triplicate in 25- $\mu \mathrm{l}$ volume.

Western blot analysis. Cell lysate preparation, SDS-PAGE, electrophoretic transfer, immunoblotting, and development using enhanced chemiluminescence were performed as previously described (14). T cells and thymocytes were fractionated either by MACS purification (Miltenyi Biotec) or FACS cell sorting. Abs to cleaved Notch1 (Val 1744), c-myc, and $\beta$-actin were purchased from Cell Signaling Technology.

Southern blot analysis. Genomic DNA $(10 \mu \mathrm{g})$ was digested with HindIII overnight at $37^{\circ} \mathrm{C}$, separated on a $1.0 \%$ agarose gel, and transferred onto nitrocellulose membrane. After UV cross-linking, the blot was hybridized with ${ }^{32} \mathrm{P}$-labeled probes from the $J \beta 1$ region of the Tcrb gene or exon 1 of $c$-myc or Rag2 and $p 53$ genes $(42,43)$.

Spectral karyotyping, chromosome painting, and FISH. Metaphases were prepared using standard protocols (colcemid treatment) and then hybridized with SKY and WCP probes from Applied Spectral Imaging according to manufacturer's instructions and/or with labeled BAC FISH probes according to standard protocols. Slides were examined under a BX61 microscope (magnification, $\times 600$ ) from Olympus, controlled by a LAMBDA 10-B Smart Shutter from Sutter Instrument. Images were captured using a LAMBDA LS light source from Sutter Instrument and a COOL-1300QS camera from Applied Spectral Imaging and then analyzed and managed through Case Data Manager version 5.5, installed, and configured by Applied Spectral Imaging.

Sequence analysis. The PEST domain of Notch1 was amplified with the following primer pairs (PEST-1: 5'-TACCAGGGCCTGCCCAACAC-3', PEST-2: 5'-GCCTCTGGAATGTGGGTGAT-3') and (PEST-3: 5'-AAGGACCTCAAGGCACGGAG-3', PEST-4: 5'-GAGGTGTGGCTGTGATGGTA-3'). PCR was performed using the same protocol as previously described (44). PCR products were gel purified, and the sequence was compared with WT Notch1.
AICD assay. $\mathrm{CD}^{+} \mathrm{T}$ cells were activated with plate-bound anti-CD3 $(1 \mu \mathrm{g} / \mathrm{ml})$ and soluble anti-CD28 $(1 \mu \mathrm{g} / \mathrm{ml})$ for 72 hours, and $100 \mathrm{U} / \mathrm{ml}$ IL-2 was added to the media for the final 24-hour culture. Cells then were harvested, and dead cells were separated by Histopaque-1083 (SigmaAldrich) density centrifugation. Viable cells were collected and restimulated with plate-bound anti-CD3 $(10 \mu \mathrm{g} / \mathrm{ml})$ overnight, and viability was measured by flow cytometry using both the vital dye 7-AAD and Annexin V (BD Biosciences - Pharmingen) as markers.

Histology. Tissues were harvested and fixed overnight at $4^{\circ} \mathrm{C}$ in $10 \%$ neutral buffered formalin. Following fixation, tissues were rinsed with cold PBS and embedded in paraffin. Tissues were sectioned $(5 \mu \mathrm{m})$ and examined by $\mathrm{H} \& \mathrm{E}$ staining. Sectioning and staining was performed by the morphology core at the University of Pennsylvania.

Crithidia luciliae assay. Anti-dsDNA antibodies were detected using fixed, permeabilized Crithidia luciliae as the substrate (Antibodies Inc.). The presence of anti-dsDNA antibody was measured by initially testing serum samples at a 1:10 dilution and detecting staining of the kinetoplast (an organelle that exclusively contains dsDNA) with an FITC-conjugated goat anti-mouse IgG reagent (Southern Biotechnology). Undetectable levels of anti-dsDNA antibodies were defined as such if no staining of the kinetoplast was seen at a 1:10 dilution. The samples were visualized under a fluorescence microscope. When anti-dsDNA antibody was detected, samples were also tested at serial 10-fold dilutions from 1:100 to 1:10,000. The serum titer was defined as the reciprocal of the last dilution at which kinetoplast staining was seen.

ELISA. Detection of serum antibodies IgG1, IgG2a, IgG3, and IgE was performed using kits purchased from BD Biosciences - Pharmingen according to the manufacturer's instructions. Briefly, 96-well flat bottom plates were coated with unlabeled goat anti-mouse $\operatorname{Ig}(\mathrm{H}+\mathrm{L})$. Following incubation with diluted sera, HRP-labeled various Ig isotypes were used as secondary reagents, and the reaction was developed using TMB substrate (BD OptEIA).

Statistics. Error bars indicate standard deviation. Statistics were calculated with a 2 -tailed Student's $t$ test. A $P$ value less than 0.05 was considered significant.

\section{Acknowledgments}

This work was supported by NIH grants AI 43620 (to Y Choi, C.H. Bassing, and L.A. Turka), CA125195 (to C.H. Bassing), and AI047833 and CA1 19070 (to W.S. Pear) and the American Society of Transplantation/American Society of Nephrology Merrill Award (to J.S. Maltzman).

Received for publication January 19, 2010, and accepted in revised form April 1, 2010.

Address correspondence to: Laurence A. Turka, The Transplant Institute, Beth Israel Deaconess Medical Center, 330 Brookline Avenue CLS 607, Boston, Massachusetts 02215, USA. Phone: 617.735.2919; Fax: 617.735.2902; E-mail: lturka@bidmc.harvard.edu.

Jodi L. Karnell's present address is: MedImmune, Gaithersburg, Maryland, USA.

Laurence A. Turka's present address is: Department of Medicine, Beth Israel Deaconess Medical Center, Harvard Medical School, Boston, Massachusetts, USA.
1. Li J, et al. PTEN, a putative protein tyrosine phosphatase gene mutated in human brain, breast, and prostate cancer. Science. 1997;275(5308):1943-1947.

2. Maehama T, Dixon JE. The tumor suppressor,
PTEN/MMAC1, dephosphorylates the lipid second messenger, phosphatidylinositol 3,4,5-trisphosphate. J Biol Chem. 1998;273(22):13375-13378.

3. Engelman JA, Luo J, Cantley LC. The evolution of phosphatidylinositol 3-kinases as regulators of growth and metabolism. Nat Rev Genet. 2006; $7(8): 606-619$

4. Teng DH, et al. MMAC1/PTEN mutations in pri- 
mary tumor specimens and tumor cell lines. Cancer Res. 1997;57(23):5221-5225.

5. Liaw D, et al. Germline mutations of the PTEN gene in Cowden disease, an inherited breast and thyroid cancer syndrome. Nat Genet. 1997;16(1):64-67.

6. Marsh DJ, et al. Mutation spectrum and genotypephenotype analyses in Cowden disease and Bannayan-Zonana syndrome, two hamartoma syndromes with germline PTEN mutation. Hum Mol Genet. 1998;7(3):507-515.

7. Gutierrez A, et al. High frequency of PTEN, PI3K, and AKT abnormalities in T-cell acute lymphoblastic leukemia. Blood. 2009;114(3):647-650.

8. Larson Gedman A, et al. The impact of NOTCH1, FBW7 and PTEN mutations on prognosis and downstream signaling in pediatric T-cell acute lymphoblastic leukemia: a report from the Children's Oncology Group. Lenkemia. 2009;23(8):1417-1425.

9. Maser RS, et al. Chromosomally unstable mouse tumours have genomic alterations similar to diverse human cancers. Nature. 2007;447(7147):966-971.

10. Hagenbeek TJ, Spits H. T-cell lymphomas in T-cellspecific Pten-deficient mice originate in the thymus. Leukemia. 2008;22(3):608-619.

11. Suzuki A, et al. T cell-specific loss of Pten leads to defects in central and peripheral tolerance. Immunity. 2001;14(5):523-534.

12. Xue L, Nolla H, Suzuki A, Mak TW, Winoto A. Normal development is an integral part of tumorigenesis in T cell-specific PTEN-deficient mice. Proc Natl Acad Sci U S A. 2008;105(6):2022-2027.

13. Finlay DK, et al. Phosphoinositide-dependent kinase 1 controls migration and malignant transformation but not cell growth and proliferation in PTEN-null lymphocytes. J Exp Med. 2009;206(11):2441-2454.

14. Buckler JL, Walsh PT, Porrett PM, Choi Y, Turka LA. Cutting edge: $\mathrm{T}$ cell requirement for CD28 costimulation is due to negative regulation of TCR signals by PTEN. I Immunol. 2006;177(7):4262-4266.

15. Di Cristofano A, Kotsi P, Peng YF, Cordon-Cardo C, Elkon KB, Pandolfi PP. Impaired Fas response and autoimmunity in Pten ${ }^{+/-}$mice. Science. 1999; 285(5436):2122-2125.

16. Guo W, et al. Multi-genetic events collaboratively contribute to Pten-null leukaemia stem-cell formation. Nature. 2008;453(7194):529-533.

17. Erikson J, et al. Deregulation of c-myc by translo- cation of the alpha-locus of the T-cell receptor in T-cell leukemias. Science. 1986;232(4752):884-886.

18. Gellert M. V(D)J recombination: RAG proteins, repair factors, and regulation. Annu Rev Biochem. 2002;71:101-132

19. Maltzman JS, Kovoor L, Clements JL, Koretzky GA. Conditional deletion reveals a cell-autonomous requirement of SLP-76 for thymocyte selection. J Exp Med. 2005;202(7):893-900.

20. Bellavia D, et al. Combined expression of pTalpha and Notch 3 in $\mathrm{T}$ cell leukemia identifies the requirement of preTCR for leukemogenesis. Proc Natl Acad Sci U S A. 2002;99(6):3788-3793.

21. Sharma VM, et al. Notch 1 contributes to mouse T-cell leukemia by directly inducing the expression of c-myc. Mol Cell Biol. 2006;26(21):8022-8031.

22. Palomero T, et al. Mutational loss of PTEN induces resistance to NOTCH1 inhibition in T-cell leukemia. Nat Med. 2007;13(10):1203-1210.

23. Weng AP, et al. c-Myc is an important direct target of Notch 1 in T-cell acute lymphoblastic leukemia/ lymphoma. Genes Dev. 2006;20(15):2096-2109.

24. Weng AP, et al. Activating mutations of NOTCH1 in human $\mathrm{T}$ cell acute lymphoblastic leukemia. Science. 2004;306(5694):269-271.

25. Palomero T, et al. NOTCH1 directly regulates c-MYC and activates a feed-forward-loop transcriptional network promoting leukemic cell growth. Proc Natl Acad Sci U S A. 2006;103(48):18261-18266.

26. Jarriault S, Brou C, Logeat F, Schroeter EH, Kopan R, Israel A. Signalling downstream of activated mammalian Notch. Nature. 1995;377(6547):355-358.

27. Aster JC, Pear WS, Blacklow SC. Notch signaling in leukemia. Annu Rev Pathol. 2008;3:587-613.

28. Sjolund J, Manetopoulos C, Stockhausen MT, Axelson $\mathrm{H}$. The Notch pathway in cancer: differentiation gone awry. Eur J Cancer. 2005;41(17):2620-2629.

29. Hagenbeek TJ, et al. The loss of PTEN allows TCR alphabeta lineage thymocytes to bypass IL-7 and Pre-TCR-mediated signaling. J Exp Med. 2004; 200(7):883-894.

30. Goodnow CC. Multistep pathogenesis of autoimmune disease. Cell. 2007;130(1):25-35.

31. Hollingsworth PN, Dawkins RI, Peter JB. Precise quantitation of antinuclear antibodies on HEp-2 cells without the need for serial dilution. Clin Diagn Lab Immunol. 1996;3(4):374-377.
32. Aarden LA, de Groot ER, Feltkamp TE. Immunology of DNA. III. Crithidia luciliae, a simple substrate for the determination of anti-dsDNA with the immunofluorescence technique. Ann NY Acad Sci. 1975;254:505-515.

33. Baker SJ. PTEN enters the nuclear age. Cell 2007;128(1):25-28.

34. Shen WH, et al. Essential role for nuclear PTEN in maintaining chromosomal integrity. Cell. 2007 ; 128(1):157-170.

35. Finger LR, Harvey RC, Moore RC, Showe LC, Croce CM. A common mechanism of chromosomal translocation in T- and B-cell neoplasia. Science. 1986; 234(4779):982-985

36. Bernard O, Larsen CJ, Hampe A, Mauchauffe M, Berger R, Mathieu-Mahul D. Molecular mechanisms of a $\mathrm{t}(8 ; 14)(\mathrm{q} 24 ; \mathrm{q} 11)$ translocation juxtaposing c-myc and TcR-alpha genes in a T-cell leukaemia: involvement of a $\mathrm{V}$ alpha internal heptamer. Oncogene. 1988;2(2):195-200.

37. Inaba $\mathrm{T}$, et al. Translocation between chromosomes $8 \mathrm{q} 24$ and $14 \mathrm{q} 11$ in T-cell acute lymphoblastic leukemia. Cancer Genet Cytogenet. 1990;49(1):69-74.

38. Soudon J, Bernard O, Mathieu-Mahul D, Larsen CJ. c-myc gene expression in a leukemic T-cell line bearing a t $(8 ; 14)$ (q24;q11) translocation. Leukemia. 1991; 5(1):60-65.

39. Bredemeyer AL, et al. DNA double-strand breaks activate a multi-functional genetic program in developing lymphocytes. Nature. 2008;456(7223):819-823.

40. Clements JL, et al. Requirement for the leukocytespecific adapter protein SLP-76 for normal T cell development. Science. 1998;281(5375):416-419.

41. Mombaerts $P$, et al. Mutations in T-cell antigen receptor genes alpha and beta block thymocyte development at different stages. Nature. 1992; 360(6401):225-231.

42. Khor B, Sleckman BP. Intra- and inter-allelic ordering of $\mathrm{T}$ cell receptor beta chain gene assembly. Eur J Immunol. 2005;35(3):964-970.

43. Zhu C, et al. Unrepaired DNA breaks in p53-deficient cells lead to oncogenic gene amplification subsequent to translocations. Cell. 2002;109(7):811-821.

44. Lin YW, Nichols RA, Letterio JJ, Aplan PD. Notch1 mutations are important for leukemic transformation in murine models of precursor-T leukemia/ lymphoma. Blood. 2006;107(6):2540-2543. 